\title{
Forest Canopy Height Estimation Using Multiplatform Remote Sensing Dataset
}

\author{
Won-Jin Lee $\mathbb{D}^{1}$ and Chang-Wook Lee $\mathbb{D}^{2}$ \\ ${ }^{1}$ Earthquake and Volcano Research Division, Korea Meteorological Administration, 61 16-Gil, Yeouidaebang-ro, Dongjak-gu, \\ Seoul 07062, Republic of Korea \\ ${ }^{2}$ Division of Science Education, 1 Kangwondaehak-gil, Chuncheon, 24341 Gangwon, Republic of Korea
}

Correspondence should be addressed to Chang-Wook Lee; cwlee@kangwon.ac.kr

Received 6 February 2017; Accepted 5 February 2018; Published 11 April 2018

Academic Editor: Oleg Lupan

Copyright (c) 2018 Won-Jin Lee and Chang-Wook Lee. This is an open access article distributed under the Creative Commons Attribution License, which permits unrestricted use, distribution, and reproduction in any medium, provided the original work is properly cited.

\begin{abstract}
Recently, numerous studies have attempted to determine forest height using remote sensing techniques that not only have the benefits of fast data acquisition, processing, and analysis but are also cost-effective. However, if there was insufficient data to apply the latest remote sensing techniques, we need to consider many kinds of datasets as possible. In this study, we tried to determine forest height using discrete-return LiDAR data, SRTM, satellite L-band SAR data, and Optical data. We experimented with the differences between LiDAR DSM and DTM, as well as SRTM DSM and LiDAR DTM. In addition, we applied an SBAS algorithm and linear regression to the dataset. From the quantitative evaluation, the RMSE and $R^{2}$ of the LiDAR-derived forest height (3.22 $\mathrm{m}$ and 0.43 , resp.) and the SRTM-derived forest height $(2.90 \mathrm{~m}$ and 0.50 , resp.) were both reasonably good, especially when we consider data acquisition time differences and measurement errors in mountainous areas. Moreover, we slightly improved the RMSE and $R^{2}$ from $2.90 \mathrm{~m}$ and 0.50 , respectively, to $2.75 \mathrm{~m}$ and 0.54 , respectively, by correcting the SRTM using the SBAS algorithm. Furthermore, we merged the datasets using linear regression and obtained improved forest heights with RMSE and $R^{2}$ values of $2.68 \mathrm{~m}$ and 0.56 , respectively. To generate a forest height map, we used NDVI from Optical imagery and masked heights below $2 \mathrm{~m}$ from each sensor. Thus, we excluded urban areas, "bare earth surfaces," and mountain streams from each sensor's imagery. Finally, we generated a forest height map by overlapping the datasets. The results of this study indicate that each sensor has the potential for not only determining forest height but also extracting complementary forest area information. Furthermore, this study demonstrates the potential for improvement using the SBAS algorithm and linear regression.
\end{abstract}

\section{Introduction}

Recently, remote sensing techniques have received a lot of attention for extracting forest information. Remote sensing techniques are efficient methods for extracting forest information not only due to fast data acquisition, processing, and analysis but also because they are cost-effective. Of the forest information which can be acquired using remote sensing data, forest height plays an important role for estimation of forest volume and aboveground biomass [1]. For these reasons, numerous studies have attempted to estimate forest height using remote sensing data such as LiDAR (Light
Detection and Ranging), Optical images, and SAR (Synthetic Aperture Radar).

Each sensor has different wavelength band for data acquisition. For example, Optical images operate with a passive sensor that uses the visible spectrum, while on the other hand, LiDAR and SAR operate active sensors using nearinfrared and microwave bands, respectively. In this sense, merging the various remote sensing data has the potential to provide reliable results for forest height extraction.

LiDAR is one of the most powerful methods for estimating forest height; therefore, many studies have attempted to merge LiDAR with Optical imagery. Shendryk et al. [2] 
combined LiDAR data and multispectral image (SPOT-5) to estimate forest canopy height using linear regression. Erdody and Moskal [3] merged airborne LiDAR and high-resolution color near-infrared imagery to estimate canopy fuel metrics in a ponderosa pine. In addition to the fusion of LiDAR and Optical images, the merging of SAR and Optical imagery has been studied [4-8].

It is worth mentioning that there are several drawbacks to each sensor. Though it has been successfully used for canopy height mapping, LiDAR data are difficult to update regularly because of the high cost [9]. Additionally, there have been studies concerned specifically with full-waveform LiDAR [10], but this data is generally not commercially available. In the case of Optical data, it has the benefit of extracting horizontal area rather than vertical structure. Meanwhile, most studies which use SAR data focus on polarimetric interferometry ([11], Damawan et al., 2014) or with using the difference in wavelengths sensitivity, such as the difference between the X-band and P-band, to calculate elevation [7]. However, it is difficult to acquire polarization and differing wavelength data, except from an airborne SAR system.

In this paper, we used available data, such as discretereturn LiDAR data, SRTM (Shuttle Radar Topography Mission), satellite L-band SAR data, and Optical data, instead of the latest data, such as full-waveform LiDAR and X- and P-band SAR data, which have been shown in previous studies to be well-suited for forest height calculation. LiDAR DTM (Digital Terrain Model) provided us with consistent terrain for a base map, and SRTM, which was constructed from short $6 \mathrm{~cm}$ wavelength, provided reflections from the surface of the forest. Abundant SAR satellite data allowed us to update the SRTM using the SBAS (Small Baseline Subset) algorithm [12] for the terrain error. Generally, Optical images has been primarily used for land cover classification, especially, NDVI (Normalized Difference Vegetation Index) which has been validated as an effective measure for identifying pixels characterized as vegetation. In summary, the determination of forest height proceeded as follows: (1) we used a variety of remote sensing data, not only air-flight data but also SAR satellite data to overcome data insufficiencies in the absence of available state-of-the-art data. (2) By applying the SBAS algorithm to the SAR images to reduce the topography error and then estimate the forest height, we extended the application of SAR satellite images based on the SBAS algorithm.

This paper is organized as follows. First, we describe the collection of the field data and provide details of the remote sensing data acquisition (LiDAR, SAR, and Optical image). We then present the methods used in the processing, and finally, we discuss the results.

\section{Study Area and Data}

2.1. Study Area. The study area for this investigation was an approximately $20 \mathrm{~km}^{2}$ area within the Jangsan Mountain in Busan, Korea (Figure 1). The altitude of the mountain is $634 \mathrm{~m}$ and the shape of the mountain is entirely conical. This area is primarily composed of pine forest with reed grass at the top of the hill. Pine trees are easy to identify top of the tree because of its shape. Therefore, measuring pine tree height is easier than broad-leaved trees (Figure 2). Also, in the area, we could collect remote-sensed data such as SAR, LiDAR, and Optical data. An in situ forest height survey was conducted throughout the entire area during September and October 2012 using laser height measurements except for artificial construction (Table 1). We determined forest height by averaging laser height measurements taken three times in opposing directions. Also, tree species composition has a major effect on forest height measurements. Therefore, we measured 90 points of in situ tree heights to only pine trees to compare with remote-sensed datasets (Table 2).

2.2. Remote-Sensed Data. We obtained SAR images from ALOS PALSAR over the study area for the period between 2007 and 2010 (Table 3). We produced 30 interferograms and used SRTM data not only to correct the topographic phase contribution but to also to estimate forest height as a DSM (Digital Surface Model). The LiDAR data were acquired in February 2007 with an LEICA ALS50 sensor, and aerial photography was acquired to generate NDVI data over the study area in April 2012. A variety of remote sensors has different resolution. In our study, we used a $5 \mathrm{~m}$ resolution LiDAR elevation model, $2.5 \mathrm{~m}$ aerial photography, $30 \mathrm{~m}$ SRTM DEM and $30 \mathrm{~m}$ SAR images using multi-look. Therefore, we conducted down- and upsampling for $5 \mathrm{~m}$ resolution after image processing.

During the processing, remote-sensed datasets include tree height error induced by acquisition time difference and sensor specification. However, these error sources are at $\mathrm{cm}$ level and do not need to be considered while ground-based tree height measurements might be more important, especially in mountain topography.

\section{Method}

3.1. Extract NDVI Using Optical Images. Optical sensors give pixel values that represent only the intensity of the light that is directly reflected from the forest surface. Therefore, this sensor is usually used for horizontal forest parameters, such as forest area, by interacting with the entire tree in particular bands. These distinct bands allow us to classify land cover, especially using the NDVI method. NDVI is defined as [13]

$$
\mathrm{NDVI}=\frac{\rho_{\text {nir }}-\rho_{\text {red }}}{\rho_{\text {nir }}+\rho_{\text {red }}},
$$

where $\rho_{\text {nir }}$ and $\rho_{\text {red }}$ are spectral reflectance measurements acquired in the near-infrared and red (visible) regions, respectively.

Several arguments have been made that NDVI is related not only to classification but also to tree height. Wang et al. [14] found that tree height increases are related to changes in NDVI from the previous year using NOAA/ AVHRR (National Oceanic and Atmospheric Administration/Advanced Very High Resolution Radiometer) satellite imagery. Therefore, we used NDVI, calculated using highgeometrical-resolution multispectral aerial images to classify forest area and to extract forest height. We obtained an NDVI map, downsampled to $5 \mathrm{~m}$ resolution using cubic 


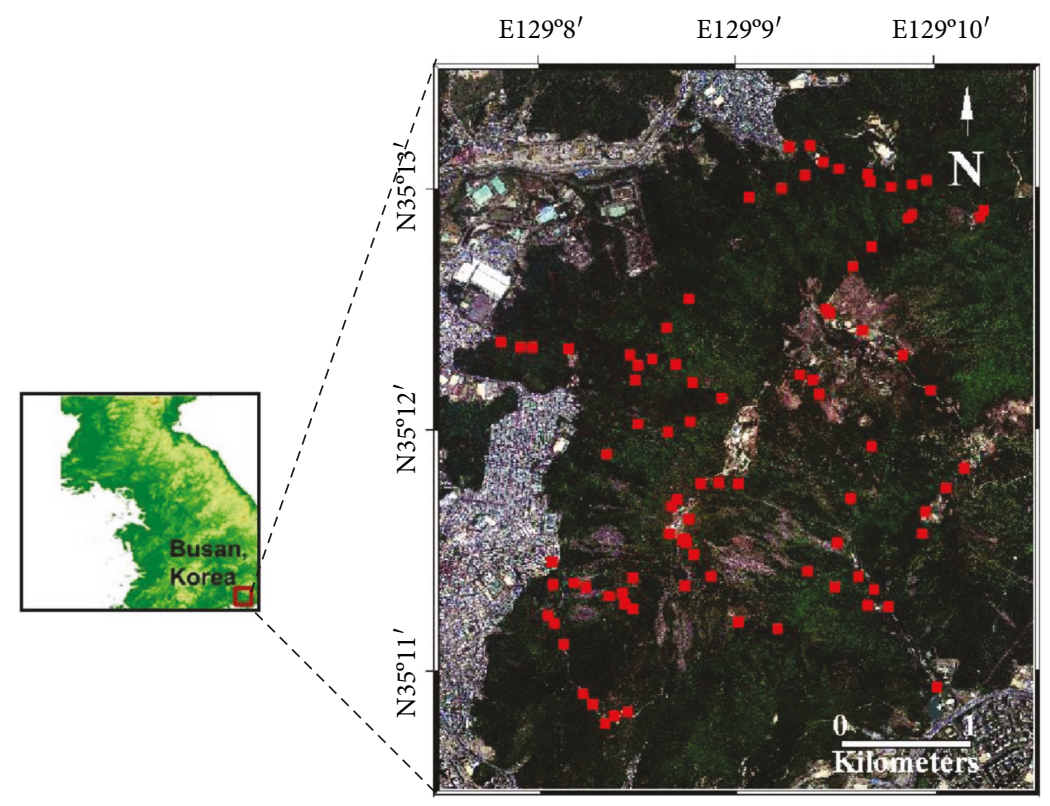

FIGURE 1: Study area and in situ locations indicated with red rectangles.
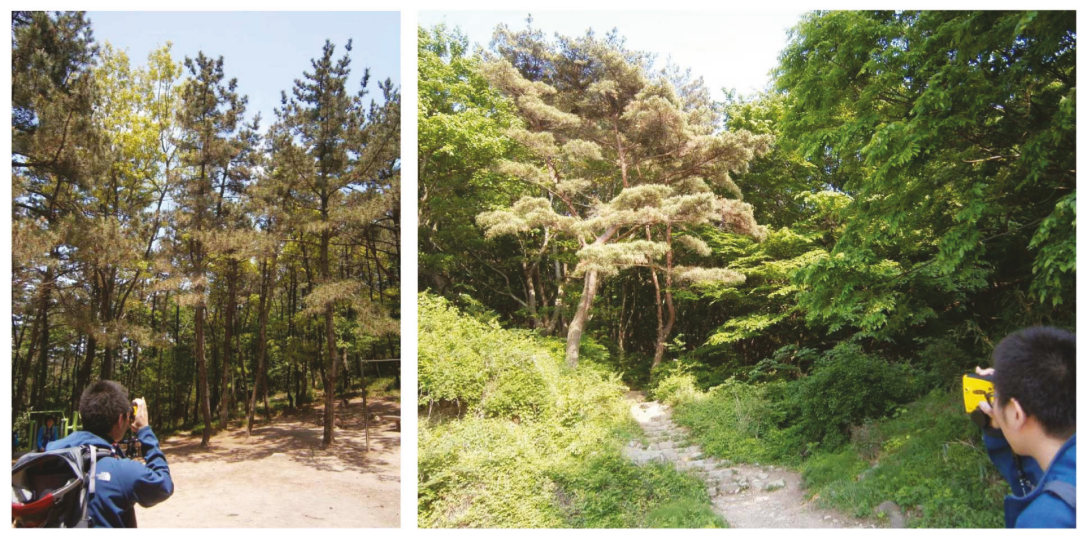

Figure 2: Field photograph.

TABLE 1: Laser measurement specification and geometry.

\begin{tabular}{lccc}
\hline Specification & Value & Picture \\
\hline Distance accuracy & $\pm 30 \mathrm{~cm}$ \\
Max range to nonreflective targets & $1000 \mathrm{~m}$ \\
Scope magnification & $7 \mathrm{x}$ & Geometry of tree height measurement using laser \\
\hline
\end{tabular}

interpolation. After knowing that NDVI has considerable noise in complex urban areas, we applied $11 \times 11$ median filtering to remove this noise (Figure 3).

3.2. LiDAR. LiDAR systems measure the range from a sensor to a target using the TOF (time of flight) of a high-frequency laser pulse. Each laser pulse is recorded as a point and provides the vertical difference between the last return (assumed as DTM) and the first return (assumed as DSM). Forest height can be determined using the difference between the DTM and the DSM [15] (Figure 4). We used discretereturn LiDAR data which was one of the available remote sensing datasets. Another role of LiDAR data is that it provides high precision DTM, which rarely changes compared to DSM.

3.3. SBAS Using $L$-Band SAR. As seen above, in cases of forest height estimation using SAR, most studies are focused on 
TABLE 2: In situ tree height measurements.

\begin{tabular}{|c|c|c|c|c|c|c|c|}
\hline Number & Latitude $\left({ }^{\circ}\right)$ & Longitude $\left({ }^{\circ}\right)$ & Height $(\mathrm{m})$ & Number & Latitude $\left({ }^{\circ}\right)$ & Longitude $\left({ }^{\circ}\right)$ & Height $(\mathrm{m})$ \\
\hline 1 & 35.19082 & 129.1346 & 18.7 & 46 & 35.20826 & 129.1576 & 8.7 \\
\hline 2 & 35.18935 & 129.1364 & 13 & 47 & 35.21124 & 129.16 & 10 \\
\hline 3 & 35.1886 & 129.1405 & 11.9 & 48 & 35.21258 & 129.1615 & 10.2 \\
\hline 4 & 35.18965 & 129.1414 & 12 & 49 & 35.21457 & 129.1645 & 9.3 \\
\hline 5 & 35.19272 & 129.1444 & 2.2 & 50 & 35.21483 & 129.1649 & 10.1 \\
\hline 6 & 35.19465 & 129.1447 & 4 & 51 & 35.20795 & 129.1579 & 3.3 \\
\hline 7 & 35.1951 & 129.1451 & 9 & 52 & 35.20684 & 129.1607 & 3.6 \\
\hline 8 & 35.19618 & 129.1471 & 6.6 & 53 & 35.20505 & 129.1642 & 10.5 \\
\hline 9 & 35.19377 & 129.146 & 5.3 & 54 & 35.20261 & 129.1664 & 10 \\
\hline 10 & 35.19627 & 129.1486 & 7.5 & 55 & 35.19725 & 129.1693 & 9.2 \\
\hline 11 & 35.19613 & 129.1503 & 13 & 56 & 35.19587 & 129.1678 & 7.6 \\
\hline 12 & 35.1921 & 129.1459 & 3.9 & 57 & 35.19429 & 129.1659 & 11 \\
\hline 13 & 35.1913 & 129.1465 & 8.4 & 58 & 35.19275 & 129.1657 & 12.6 \\
\hline 14 & 35.18977 & 129.148 & 10.3 & 59 & 35.18768 & 129.1629 & 13.8 \\
\hline 15 & 35.1866 & 129.1503 & 8.9 & 60 & 35.21848 & 129.1575 & 12.67 \\
\hline 16 & 35.18612 & 129.1535 & 12.2 & 61 & 35.21796 & 129.1588 & 14.83 \\
\hline 17 & 35.18902 & 129.1584 & 9.4 & 62 & 35.21764 & 129.1611 & 13.38 \\
\hline 18 & 35.18975 & 129.1604 & 13.4 & 63 & 35.21686 & 129.1649 & 12.13 \\
\hline 19 & 35.1878 & 129.1612 & 14.4 & 64 & 35.21459 & 129.1707 & 12.33 \\
\hline 20 & 35.18212 & 129.1669 & 14.4 & 65 & 35.21509 & 129.171 & 9.05 \\
\hline 21 & 35.18043 & 129.1409 & 4.4 & 66 & 35.21716 & 129.1661 & 10.18 \\
\hline 22 & 35.18015 & 129.1398 & 5 & 67 & 35.21669 & 129.1631 & 11.45 \\
\hline 23 & 35.17964 & 129.1391 & 12.5 & 68 & 35.21707 & 129.1614 & 13.4 \\
\hline 24 & 35.18095 & 129.1379 & 11 & 69 & 35.21963 & 129.1563 & 16.27 \\
\hline 25 & 35.18169 & 129.1371 & 13 & 70 & 35.21953 & 129.1546 & 7.47 \\
\hline 26 & 35.18513 & 129.1355 & 12 & 71 & 35.20605 & 129.1303 & 18.5 \\
\hline 27 & 35.18654 & 129.1348 & 7.5 & 72 & 35.20568 & 129.132 & 15.45 \\
\hline 28 & 35.18705 & 129.1342 & 13.5 & 73 & 35.20563 & 129.1329 & 14.183 \\
\hline 29 & 35.18925 & 129.1346 & 12.5 & 74 & 35.20554 & 129.136 & 13.73 \\
\hline 30 & 35.18907 & 129.1374 & 12.2 & 75 & 35.20508 & 129.1412 & 17.33 \\
\hline 31 & 35.18844 & 129.1394 & 9.3 & 76 & 35.207 & 129.1443 & 11.73 \\
\hline 32 & 35.18786 & 129.1407 & 7.7 & 77 & 35.20898 & 129.1461 & 10.57 \\
\hline 33 & 35.18757 & 129.1414 & 7.2 & 78 & 35.21604 & 129.1512 & 12.7 \\
\hline 34 & 35.19229 & 129.1455 & 2.5 & 79 & 35.21665 & 129.1539 & 17.53 \\
\hline 35 & 35.19237 & 129.1458 & 3.2 & 80 & 35.21749 & 129.1559 & 13.58 \\
\hline 36 & 35.18916 & 129.1458 & 3.5 & 81 & 35.20037 & 129.1418 & 6.55 \\
\hline 37 & 35.1901 & 129.1561 & 12 & 82 & 35.2034 & 129.1416 & 13 \\
\hline 38 & 35.18882 & 129.1616 & 16.5 & 83 & 35.20438 & 129.1418 & 12.92 \\
\hline 39 & 35.19211 & 129.1586 & 7.8 & 84 & 35.20487 & 129.143 & 11.92 \\
\hline 40 & 35.19514 & 129.1597 & 10.8 & 85 & 35.20452 & 129.145 & 8.1 \\
\hline 41 & 35.1988 & 129.1615 & 11 & 86 & 35.20318 & 129.1465 & 7.98 \\
\hline 42 & 35.20238 & 129.157 & 9 & 87 & 35.20212 & 129.1488 & 9.73 \\
\hline 43 & 35.20337 & 129.1565 & 8.3 & 88 & 35.20053 & 129.1462 & 10.27 \\
\hline 44 & 35.20377 & 129.1555 & 9.9 & 89 & 35.19975 & 129.1443 & 10.27 \\
\hline 45 & 35.20377 & 129.1555 & 8 & 90 & 35.1983 & 129.1392 & 16.08 \\
\hline
\end{tabular}

polarimetry and the penetration capabilities of the bands. Considered in this framework, it is necessary to use polarization data, such as TerraSAR-X, and air vehicles with long wavelengths, such as a P-band SAR sensor. These systems, however, are still experimental or generally are not commercially available in our study area; therefore, instead of these 
TABLE 3: SAR pairs for this study.

\begin{tabular}{|c|c|c|c|}
\hline Master & Slave & Perp baseline $(\mathrm{m})$ & Date difference \\
\hline 20070915 & 20071031 & 536 & 46 \\
\hline 20071031 & 20071216 & 135 & 46 \\
\hline 20071031 & 20080131 & 572 & 92 \\
\hline 20071031 & 20080317 & 683.0 & 138 \\
\hline 20071031 & 20100205 & -353.0 & 828 \\
\hline 20071031 & 20100508 & 115 & 920 \\
\hline 20071216 & 20080131 & 437 & 46 \\
\hline 20071216 & 20100205 & -489 & 782 \\
\hline 20071216 & 20100508 & -20 & 874 \\
\hline 20080131 & 20080317 & 110 & 46 \\
\hline 20080131 & 20080502 & 750 & 92 \\
\hline 20080131 & 20100205 & -926 & 736 \\
\hline 20080131 & 20101224 & 425 & 1058 \\
\hline 20080317 & 20080502 & 639 & 46 \\
\hline 20080617 & 20090202 & -269 & 230 \\
\hline 20080617 & 20090805 & 66 & 414 \\
\hline 20080917 & 20090202 & 893 & 138 \\
\hline 20090202 & 20090805 & 336 & 184 \\
\hline 20090805 & 20090920 & 605 & 46 \\
\hline 20090805 & 20091105 & 1037 & 92 \\
\hline 20090920 & 20091105 & 432 & 46 \\
\hline 20090920 & 20091221 & 658 & 92 \\
\hline 20091105 & 20091221 & 225 & 46 \\
\hline 20091105 & 20100205 & 754 & 92 \\
\hline 20091105 & 20100508 & 1223 & 184 \\
\hline 20091221 & 20100205 & 528 & 46 \\
\hline 20091221 & 20100508 & 997 & 138 \\
\hline 20100205 & 20100508 & 468 & 92 \\
\hline 20100508 & 20100808 & 351 & 92 \\
\hline 20100508 & 20101224 & 883 & 230 \\
\hline
\end{tabular}

systems, we used ALOS PALSAR SAR imagery to overcome data deficiency and we increased accuracy using the SBAS algorithm. We generated a differential interferogram to apply the SBAS algorithm by using the interferograms simulated from the SRTM DEM that were multi-looked using three looks in range and twelve looks in azimuth, respectively. We used SRTM DEM for the differential interferogram, in spite of having higher accuracy LiDAR DTM because the latter covered only a small part of the SAR image. As a result, we estimated the topography error using the SBAS algorithm with the differential interferogram. For the SBAS algorithm, the differential phase is as follows:

$$
\begin{aligned}
\Delta \varphi_{i, j}(x, r)= & \Delta \varphi_{i}(x, r)-\Delta \varphi_{j}(x, r) \\
\approx & \frac{4 \pi}{\lambda}\left[d_{i}(x, r)-d_{j}(x, r)\right]+\frac{4 \pi}{\lambda} \frac{B_{\perp i, j} \Delta z}{R \sin \theta} \\
& +\left[\varphi_{i}^{\mathrm{atm}}(x, r)-\varphi_{j}^{\mathrm{atm}}(x, r)\right]+\Delta n_{i, j}
\end{aligned}
$$

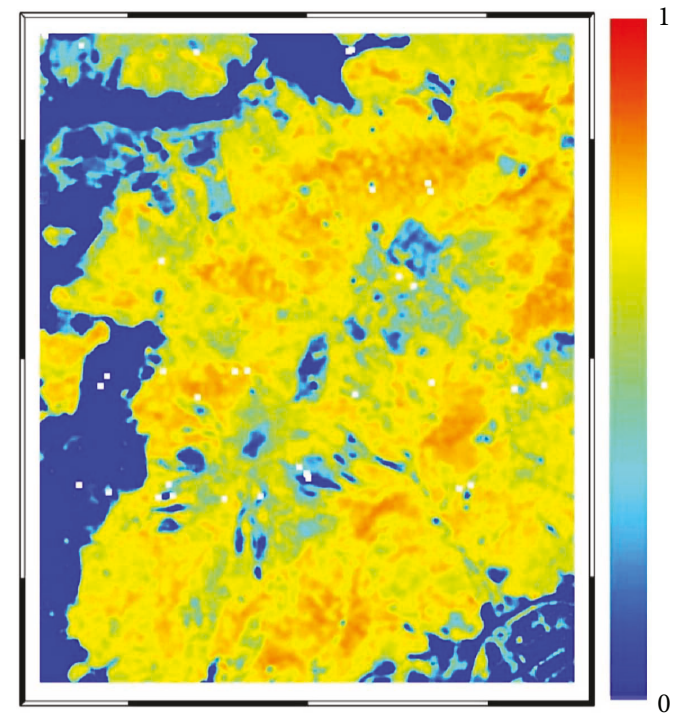

Figure 3: NDVI map after median filtering.

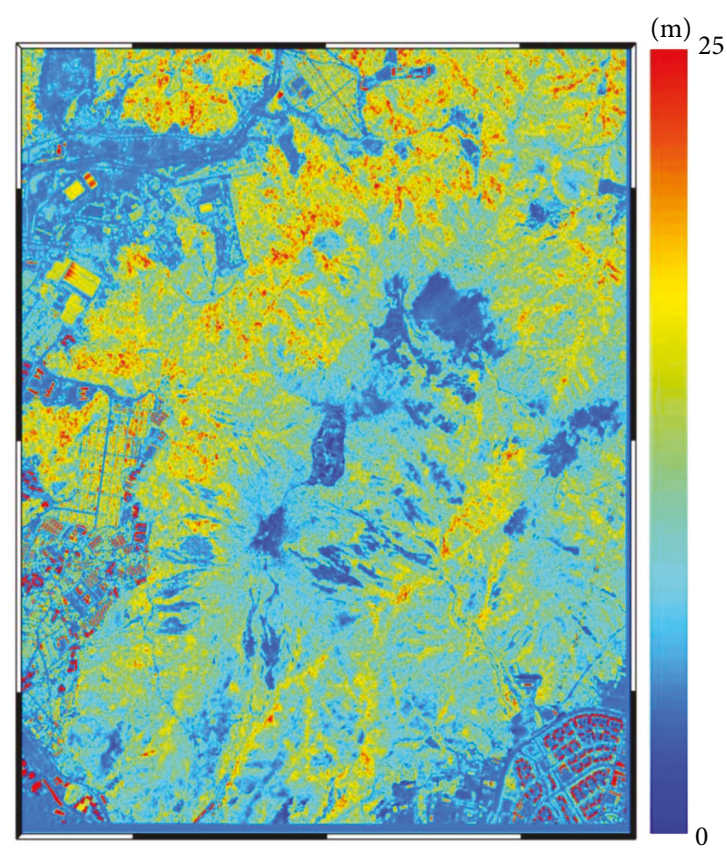

FIgURE 4: LiDAR height map by DSM-DTM.

where $\varphi$ is the phase and $i, j$ are time variables for master and slave acquisition time, $d$ is surface displacement, $x$ and $r$ are azimuth and slant-range pixel coordinates, $\lambda$ is radar wavelength, $B_{\perp}$ is the perpendicular baseline, $R$ is the slant-range distance from sensor to pixel, and $\theta$ is the look angle. The first term accounts for the deformation phase, the second term accounts for topography error, the third is the atmosphere effect on the phase, and the last term accounts for phase noise by decorrelation or noise effect.

From (2), the first term of the deformation phase was not considered because the study area is stable and the third term of the atmosphere effect was neglected because we assumed that the sum of the atmospheric effects are 


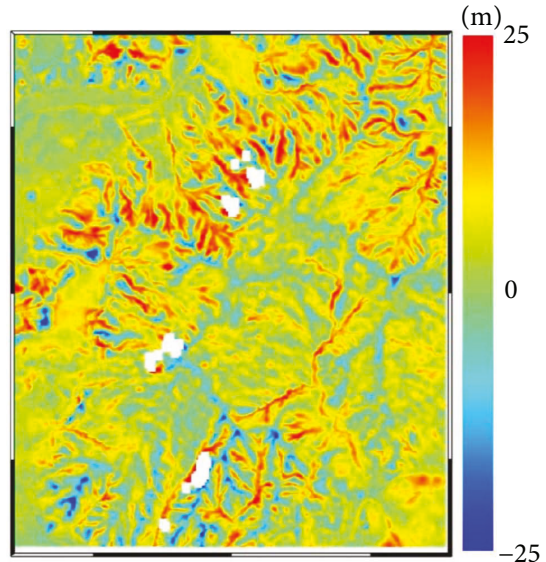

(a)

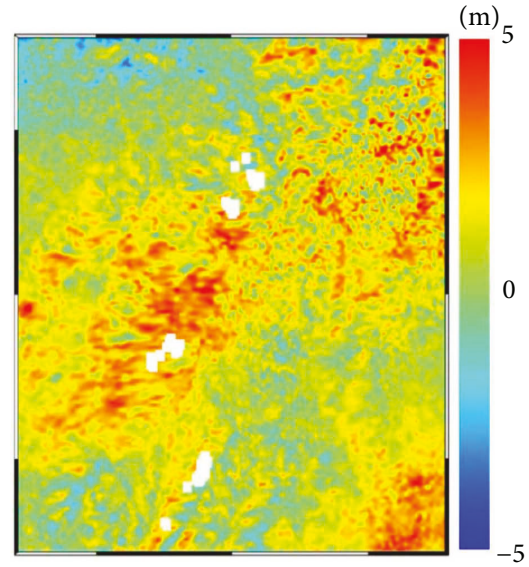

(b)

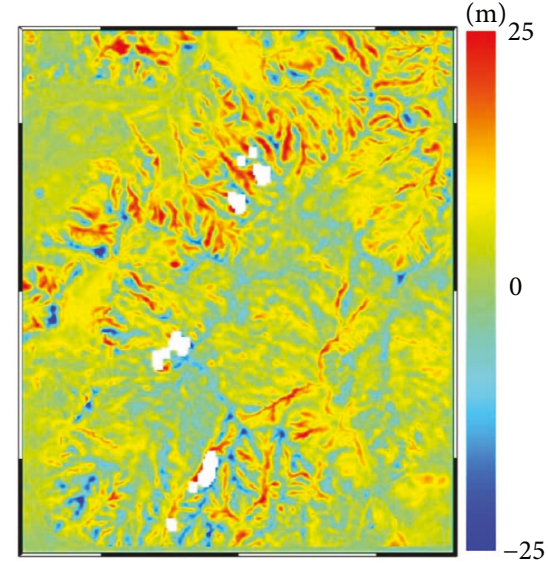

(c)

Figure 5: (a) SRTM DEM-LiDAR DTM, (b) topography error by SBAS, and (c) SRTM DEM-LiDAR DTM-SBAS topography error.

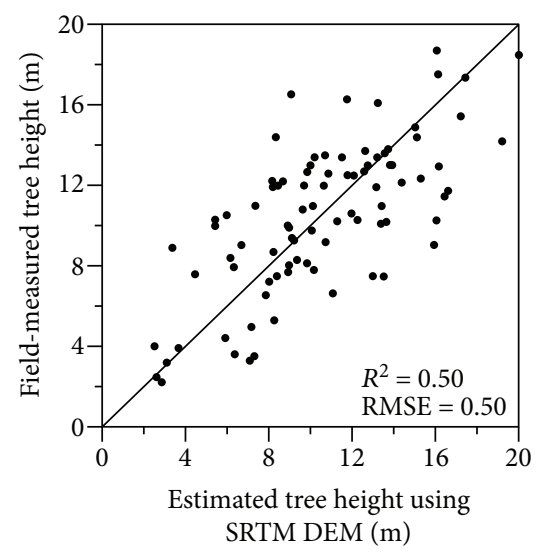

(a)

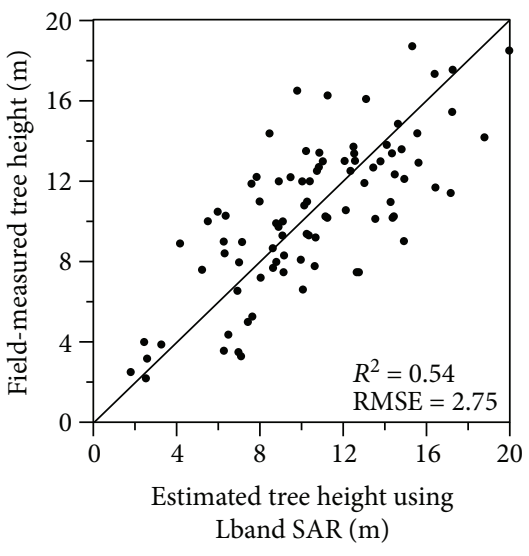

(b)

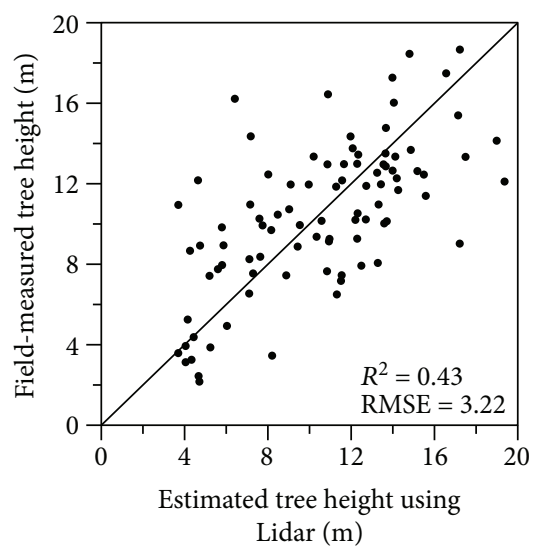

(c)

FIgURE 6: (a) Tree height derived by SRTM-DTM, (b) tree height derived by SRTM-DTM-height error, and (c) tree height derived by LiDAR.

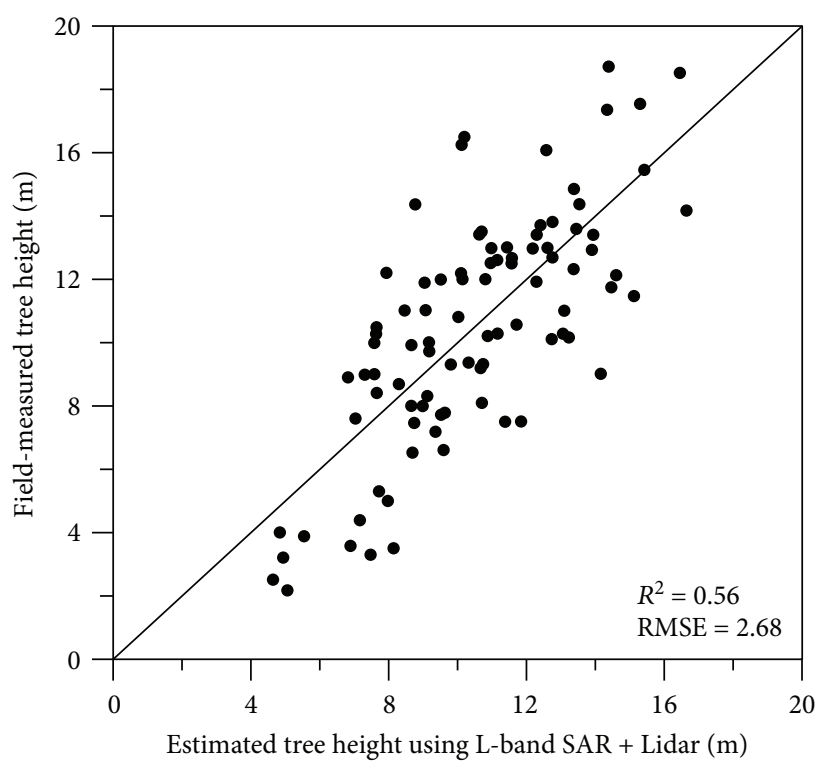

(a)

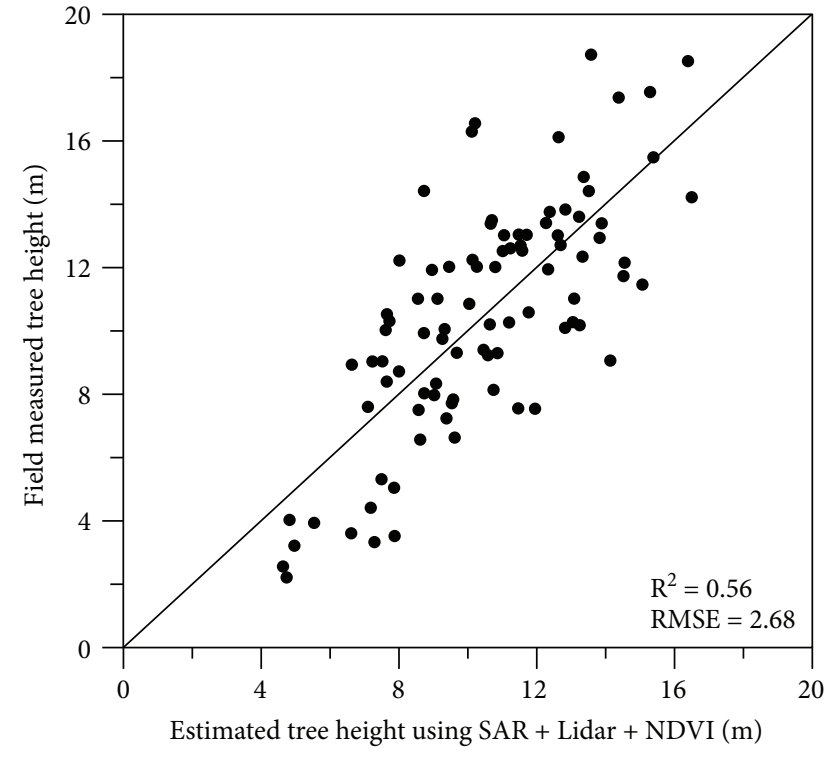

(b)

FIgure 7: (a) Tree height derived by SAR and LiDAR and (b) tree height derived by SAR and LiDAR and NDVI. 

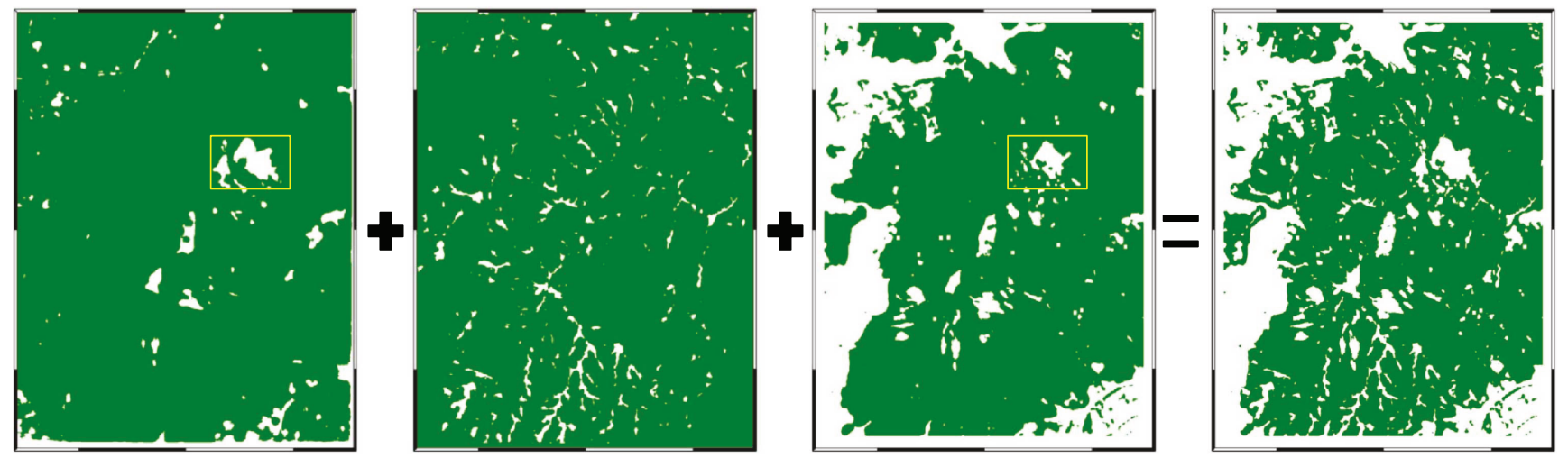

Figure 8: Masking forest area map by overlapping LiDAR, SAR, and NDVI and the yellow box represents "bare earth surfaces".

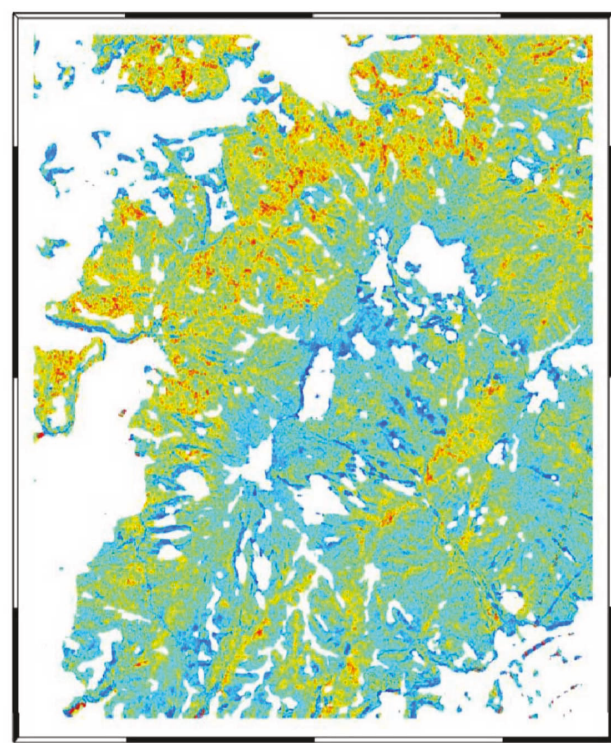

(a)

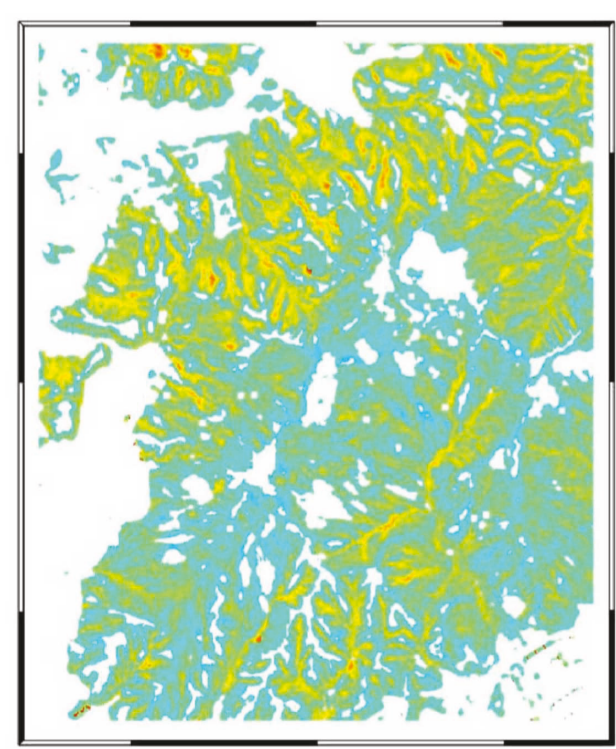

(c)
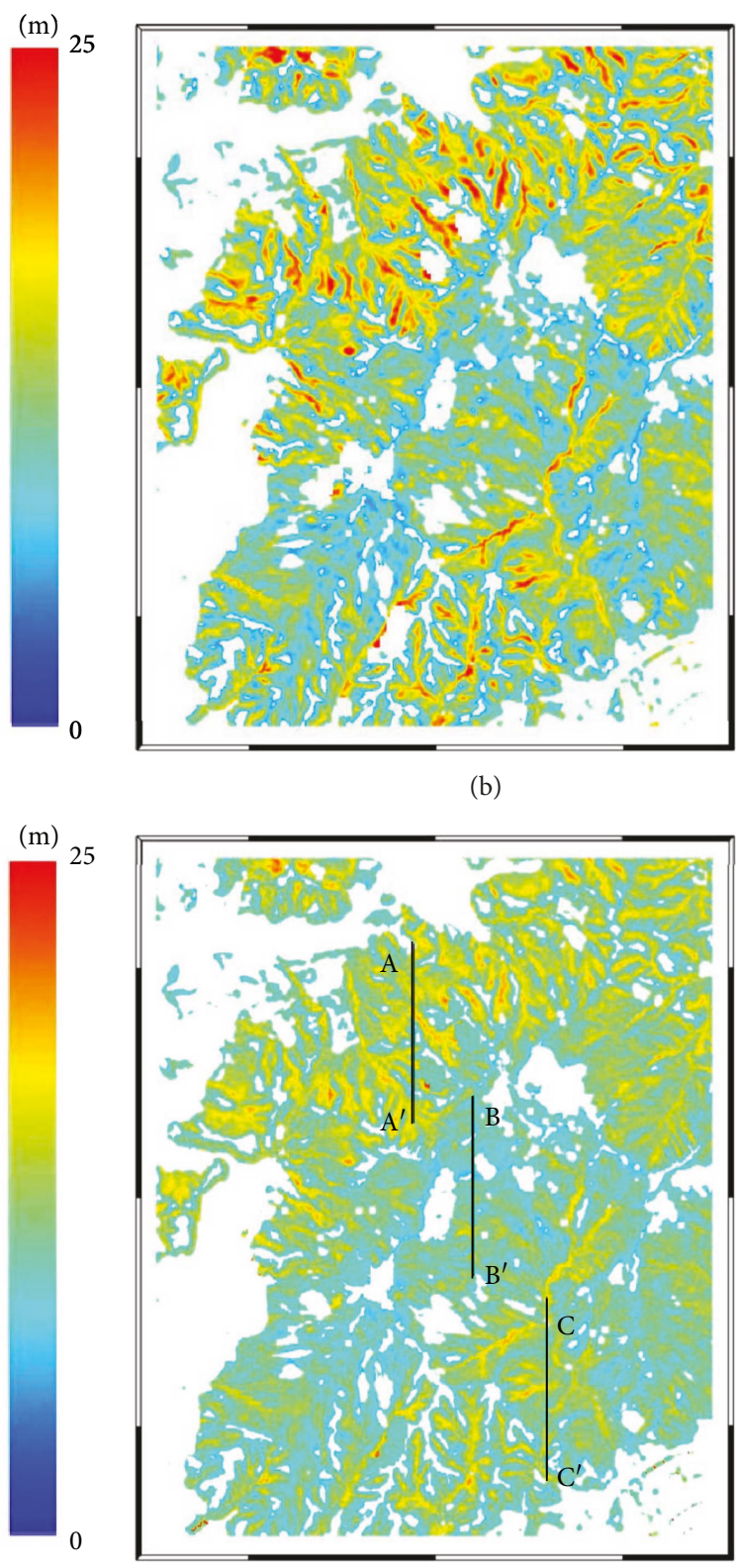

(d)

Figure 9: Forest height map derived by (a) LiDAR, (b) SAR, (c) LiDAR + SAR, and (d) LiDAR + SAR + NDVI. 
random with respect to time similar to phase noise, so that is $\sum_{i} \varphi_{i}^{\text {atm }}(x, r) \approx 0$ and $\sum_{i} \Delta n_{i} \approx 0$. As a result, we defined topography error $(\Delta z)$ iteratively as [16]

$$
\Delta z=\frac{\lambda}{4 \pi} R \sin \theta \frac{\Delta \varphi_{i, j}(x, r)}{B_{\perp i, j}} .
$$

The topography error shown in Figure 5(b) from the SBAS algorithm represents the C-band-derived SRTM DEM error. Therefore, we estimated forest height from the difference between the SRTM DEM and the LiDAR DTM using a regression model (Figure 5(a)) and then we made a forest height map using DEM correction (Figure 5(c)). Moreover, we estimated and analyzed forest height using linear regression on combined LiDAR, SAR, and NDVI data.

\section{Results and Discussion}

4.1. Estimated Forest Height. We conducted comparisons between the SRTM-derived forest height and the topographically corrected SRTM-derived forest height with respect to in situ dataset (Figures 6(a) and 6(b)). The root mean square error of the estimated forest height from the first method to the second method was a little improved, from 2.90 to 2.75 as well as the $R^{2}$ increasing from 0.50 to 0.54 . In the case of the LiDAR data, the RMSE and $R^{2}$ were calculated at $3.22 \mathrm{~m}$ and 0.43 , respectively (Figure 6(c)); however, when the data acquisition differences between LiDAR and the in situ data are taken into consideration, particularly for the mountainous topography of the study area, these results show that this method is viable for determining forest height.

To improve the results, we merged the data through linear combination as follows:

$$
\begin{aligned}
H_{\text {TreeHeight_1 }}= & \alpha \cdot H_{\text {SARHeight }}+\beta \cdot H_{\text {LiDARHeight }}+c, \\
H_{\text {TreeHeight_2 }}= & d \cdot H_{\text {SARHeight }}+e \cdot H_{\text {LiDARHeight }} \\
& +f \cdot H_{\text {NDVIHeight }}+g,
\end{aligned}
$$

where $\alpha, \beta, d, e$, and $f$ are coefficients and $c$ and $f$ are offset values obtained from each tree height data and a least squares technique.

From (4), the RMSE of the forest height derived from the combined data improved by approximately $10 \mathrm{~cm}$ and $50 \mathrm{~cm}$ from the SAR-derived forest height and the LiDARderived forest height, respectively. This approach may be the most viable method to determine forest height (Figure 7(a)). In the case of NDVI, there have been accounts that there is a relationship between NDVI and tree height [14]; however, it was not possible to estimate forest height using this method for this study because most of the trees in the study area have minor stem diameters and tree rings (Figure $7(b)$ ).

4.2. Forest Area Mapping. We extracted forest height based on LiDAR DTM; however, this method led to unexpected forest areas such as urban area (artificial buildings) or field of reeds. To remove urban areas from the forest height map, we calculated NDVI values using aerial Optical imagery which has NIR and R-bands. First, we masked below $2 \mathrm{~m}$ in
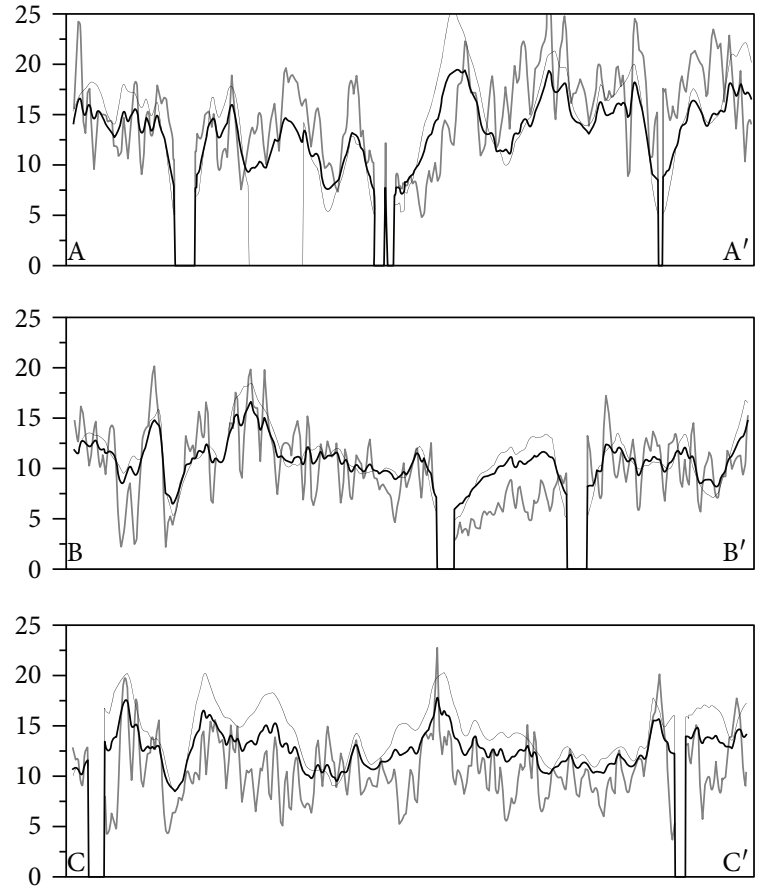

FIgURE 10: Forest height profile presented in Figure 9. Grey line represents LiDAR-derived height, black line represents SARderived line, black bold line represents $\mathrm{LiDAR}+\mathrm{SAR}$-derived height. LiDAR + SAR + NDVI-derived height has same profile value with black bold line.

height from LiDAR- and SAR-derived height maps because we only collect over $2 \mathrm{~m}$ in height trees. From the first masking results, the urban area remained as a forest area having both LiDAR- and SAR-derived height maps in common because artificial structures were above the threshold. Furthermore, SAR dataset excluded mountain streams in valley areas. To be precise, there are thin forest areas along the streams that the L-band penetrates more deeply than dense forest areas. Additionally, the "bald earth surface" areas signified construction dated after the SRTM DEM was acquired because the "bald earth surfaces" are not presented in the SAR-derived forest area map. Second, we used an NDVI value for threshold 0.4 as a nonforest area to remove the urban area.

Finally, we generated a forest area map by overlapping three datasets (Figure 8) and generated a forest height map using LiDAR, SAR, NDVI data, and a linear combination of each dataset and forest area (Figure 9). To compare results, we generated a height profile (Figure 10). The profile shows that LiDAR-derived forest height well represents detailed changes while SAR-derived forest height represents the overall pattern well. If we used two merged datasets, we represent not only overall pattern but also detailed change over the forest area. However, NDVI factor have no influence to forest height retrieval.

\section{Conclusion}

Remote sensing techniques are efficient methods of extracting forest height quickly, with cost-effective tools. However, there is data insufficiency for our study area with regard to 
the latest data, such as full-waveform LiDAR and X- and Pband SAR data. Instead, we determined forest height using common remote data, such as discrete-return LiDAR data, SRTM, satellite L-band SAR data, and Optical data. Moreover, in order to improve the results, we applied the SBAS algorithm for SRTM DEM error correction and combined each dataset using linear regression. We then extracted the forest areas by overlapping NDVI and forest height data above $2 \mathrm{~m}$ allowing the sensors to complement each other. Using this procedure, we generated a forest height map as an end product with an RMSE accuracy of $2.68 \mathrm{~m}$.

In general terms, this study shows the various ways in generating a forest height map using limited data. In spite of different acquisition times, it should be noted that each sensor has the potential for not only determining forest height but also extracting complementary forest area. Furthermore, there is potential for improvement using the SBAS algorithm and linear regression. For those who may encounter a lack of available of data to generate forest height map, this study offers one possible approach.

\section{Conflicts of Interest}

The authors declare that they have no conflicts of interest.

\section{Acknowledgments}

This research was supported by the National Research Foundation of Korea (NRF) grant funded by the Korea government (MSIP) (no. NRF-2017R1A2B4003258) and Basic Science Research Program through the National Research Foundation of Korea (NRF) funded by the Ministry of Science, ICT \& Future Planning (NRF2015M1A3A3A02013416).

\section{References}

[1] W. A. Mugasha, E. E. Mwakalukwa, E. Luoga et al., "Allometric models for estimating tree volume and aboveground biomass in lowland forests of Tanzania," International Journal of Forestry Research, vol. 2016, Article ID 8076271, 13 pages, 2016.

[2] I. Shendryk, M. Hellström, L. Klemedtsson, and N. Kljun, "Low-density LiDAR and optical imagery for biomass estimation over boreal forest in Sweden," Forests, vol. 5, no. 12, pp. 992-1010, 2014.

[3] T. L. Erdody and L. M. Moskal, "Fusion of LiDAR and imagery for estimating forest canopy fuels," Remote Sensing of Environment, vol. 114, no. 4, pp. 725-737, 2010.

[4] M. García, S. Saatchi, S. Ustin, and H. Balzter, "Modelling forest canopy height by integrating airborne LiDAR samples with satellite radar and multispectral imagery," International Journal of Applied Earth Observation and Geoinformation, vol. 66, pp. 159-173, 2018.

[5] J. M. Kellndorfer, W. S. Walker, E. LaPoint, K. Kirsch, J. Bishop, and G. Fiske, "Statistical fusion of Lidar, InSAR, and optical remote sensing data for forest stand height characterization: a regional-scale method based on LVIS, SRTM, Landsat ETM+, and ancillary data sets," Journal of Geophysical Research, vol. 115, no. G2, 2010.
[6] S. Luo, C. Wang, X. Xi et al., "Fusion of airborne LiDAR data and hyperspectral imagery for aboveground and belowground forest biomass estimation," Ecological Indicators, vol. 73, pp. 378-387, 2017.

[7] J. O. Sexton, T. Bax, P. Siqueira, J. J. Swenson, and S. Hensley, "A comparison of Lidar, radar, and field measurements of canopy height in pine and hardwood forests of southeastern North America," Forest Ecology and Management, vol. 257, no. 3, pp. 1136-1147, 2009.

[8] W. S. Walker, J. M. Kellndorfer, E. LaPoint, M. Hoppus, and J. Westfall, "An empirical InSAR-optical fusion approach to mapping vegetation canopy height," Remote Sensing of Environment, vol. 109, no. 4, pp. 482-499, 2007.

[9] M. Sprintsin, P. Berliner, S. Cohen, and A. Karnieli, "Using multispectral spaceborne imagery to assess mean tree height in a dryland plantation," ISRN Forestry, vol. 2013, Article ID 485264, 8 pages, 2013.

[10] K. Lim, P. Treitz, M. Wulder, B. St-Onge, and M. Flood, "LiDAR remote sensing of forest structure," Progress in Physical Geography, vol. 27, no. 1, pp. 88-106, 2016.

[11] F. Garestier, P. C. Dubois-Fernandez, and K. P. Papathanassiou, "Pine forest height inversion using single-pass X-band PolInSAR data," IEEE Transactions on Geoscience and Remote Sensing, vol. 46, no. 1, pp. 59-68, 2008.

[12] P. Berardino, G. Fornaro, R. Lanari, and E. Sansosti, "A new algorithm for surface deformation monitoring based on small baseline differential SAR interferograms," IEEE Transactions on Geoscience and Remote Sensing, vol. 40, no. 11, pp. 23752383, 2002.

[13] J. W. Rouse, R. H. Haas, J. A. Schell, and D. W. Deering, "Monitoring vegetation systems in the great plains with ERTS," Third ERTS Symposium NASA, vol. SP-351, no. I, pp. 309317, 1973.

[14] J. Wang, P. M. Rich, K. P. Price, and W. D. Kettle, "Relations between NDVI and tree productivity in the central Great Plains," International Journal of Remote Sensing, vol. 25, no. 16, pp. 3127-3138, 2004.

[15] R. C. Parker and D. L. Evans, "LiDAR forest inventory with single-tree, double-, and single-phase procedures," International Journal of Forestry Research, vol. 2009, Article ID 864108, 6 pages, 2009.

[16] H. S. Jung, C. W. Lee, J. W. Park, K. D. Kim, and J. S. Won, "Improvement of small baseline subset (SBAS) algorithm for measuring time-series surface deformation from differential SAR interferograms," Korean Society of Remote Sensing, vol. 24, no. 2, pp. 165-177, 2008. 


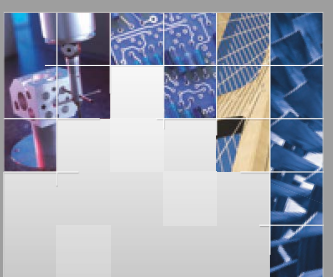

\section{Enfincering}
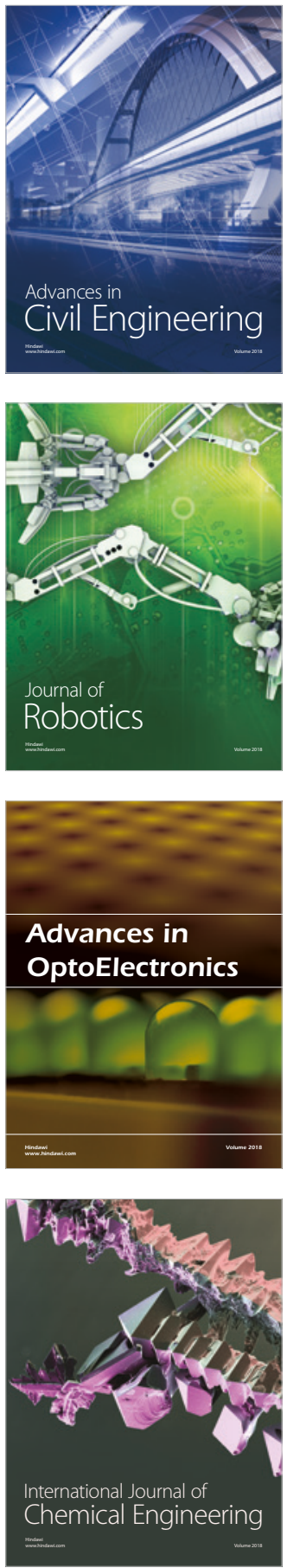

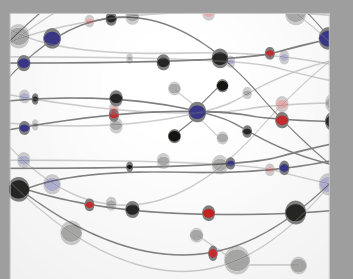

\section{Rotating \\ Machinery}

The Scientific World Journal

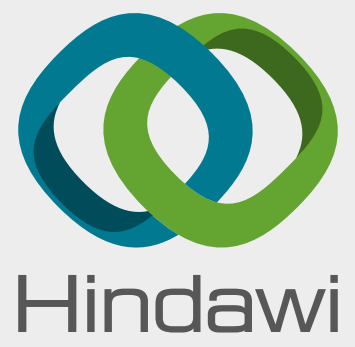

Submit your manuscripts at

www.hindawi.com
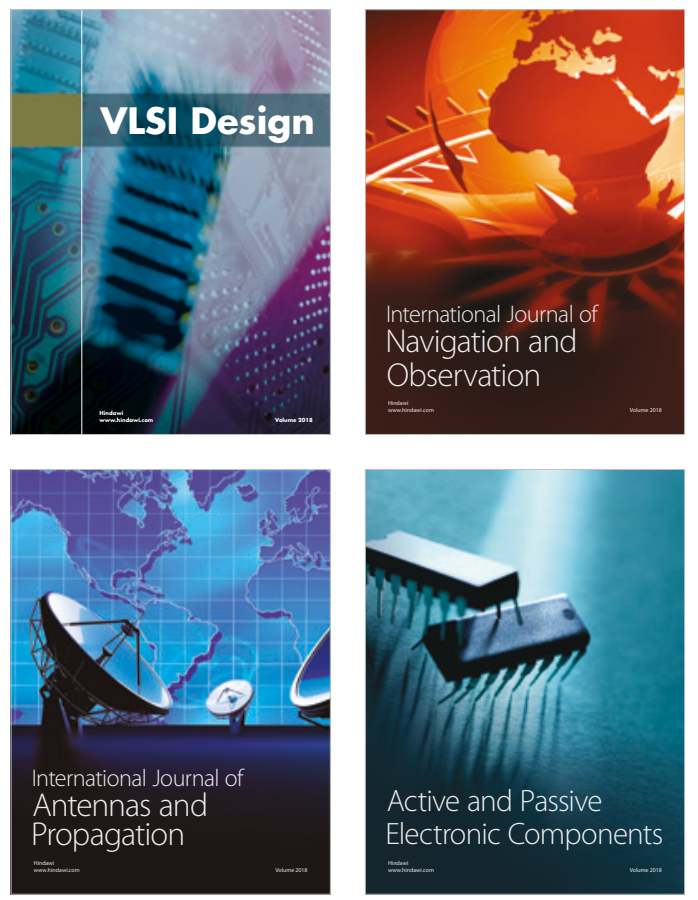
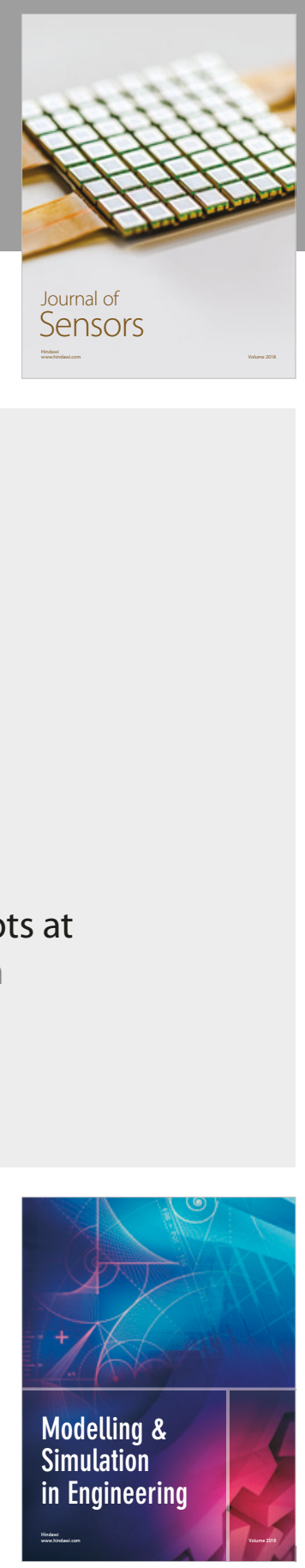

\section{Advances \\ Multimedia}
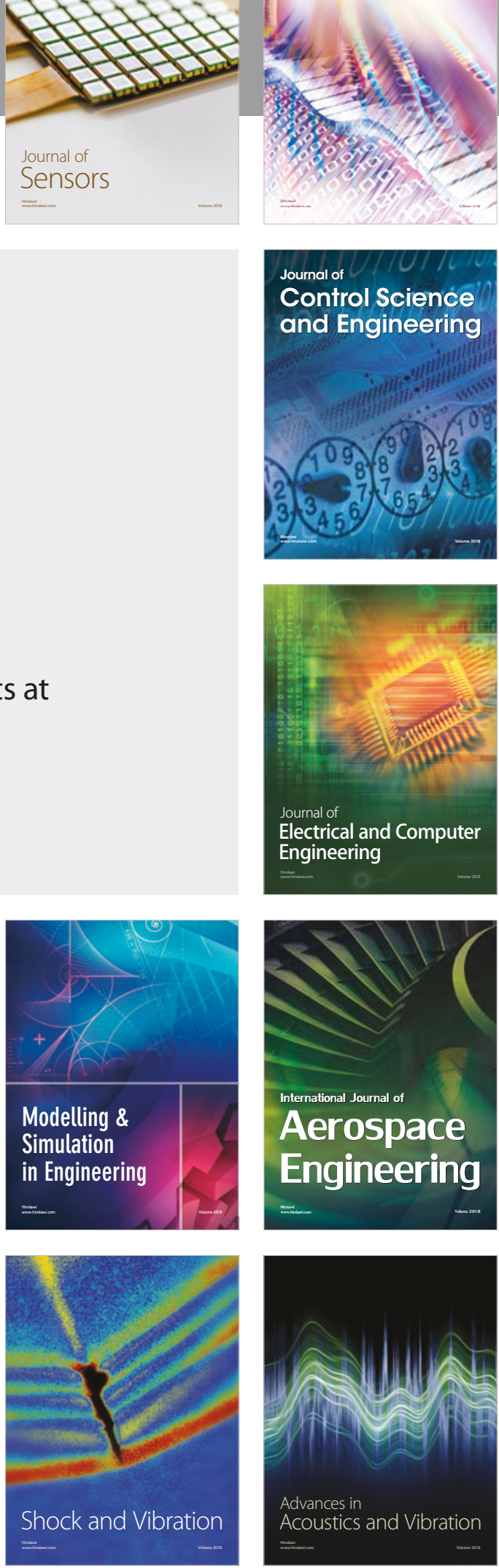